\title{
Prognostic Validity of the American Joint Committee on Cancer Eighth Edition Staging System for Well-Differentiated Pancreatic Neuroendocrine Tumors: A Retrospective Multinational Multicenter Study
}

\section{Hebin Wang}

Tongji Hospital of Tongji Medical College of Huazhong University of Science and Technology

\section{Ding Ding}

Johns Hopkins School of Medicine: Johns Hopkins University School of Medicine

\section{Tingting Qin}

Tongji Hospital of Tongji Medical College of Huazhong University of Science and Technology

Jun Liu

Shandong Provincial Hospital

\section{Hang Zhang}

Tongji Hospital of Tongji Medical College of Huazhong University of Science and Technology Junfang Zhao

Tongji Hospital of Tongji Medical College of Huazhong University of Science and Technology

\section{Chien-Hui Wu}

National Taiwan University Hospital

\section{Ammar Javed}

Johns Hopkins Hospital: Johns Hopkins Medicine

\section{Christopher Wolfgang}

Johns Hopkins Hospital: Johns Hopkins Medicine

Shiwei Guo

Changhai Hospital

\section{Qinmin Chen}

Jilin University First Hospital

\section{Weihong Zhao}

Hebei Medical University No2 Hospital: Second Hospital of Hebei Medical University

Wei Shi

Shandong Provincial Hospital

\section{Feng Zhu}

Tongji Hospital of Tongji Medical College of Huazhong University of Science and Technology

\section{Xingjun Guo}

Tongji Hospital of Tongji Medical College of Huazhong University of Science and Technology

Xu Li

Tongji Hospital of Tongji Medical College of Huazhong University of Science and Technology

\section{Feng Peng}

Tongji Hospital of Tongji Medical College of Huazhong University of Science and Technology

Ruizhi He

Tongji Hospital of Tongji Medical College of Huazhong University of Science and Technology

Simiao Xu

Tongji Hospital of Tongji Medical College of Huazhong University of Science and Technology

Jikuan Jin

Tongji Hospital of Tongji Medical College of Huazhong University of Science and Technology 


\section{Yi Wu}

Tongji Hospital of Tongji Medical College of Huazhong University of Science and Technology

Abula Nuer

Tongji Hospital of Tongji Medical College of Huazhong University of Science and Technology

\section{Barish Edil}

The University of Oklahoma

\section{Yu-Wen Tien}

National Taiwan University

\section{Gang Jin}

Changhai Hospital

\section{Lei Zheng}

Johns Hopkins Hospital: Johns Hopkins Medicine

Jin $\mathrm{He}$

Johns Hopkins Hospital: Johns Hopkins Medicine

\section{Jianhua Liu}

Hebei Medical University No2 Hospital: Second Hospital of Hebei Medical University

\section{Yahui Liu}

Jilin University First Hospital

\section{Min Wang}

Tongji Hospital of Tongji Medical College of Huazhong University of Science and Technology

\section{Renyi Qin ( $\nabla$ ryqin@tjh.tjmu.edu.cn )}

Tongji Hospital of Tongji Medical College of Huazhong University of Science and Technology

\section{Research}

Keywords: Pancreatic neuroendocrine tumors, staging, survival, prognosis

Posted Date: October 8th, 2020

DOI: https://doi.org/10.21203/rs.3.rs-86061/v1

License: @ (1) This work is licensed under a Creative Commons Attribution 4.0 International License. Read Full License 


\section{Abstract}

\section{Background:}

There is no widely-accepted staging system for pancreatic neuroendocrine tumors (pNETs). The aim of this study was to validate the American Joint Committee on Cancer (AJCC) 8th edition staging system for well-differentiated (G1/G2) pNETs.

\section{Methods:}

A multicenter dataset $(n=1086)$ was used to evaluate the application of the AJCC $7^{\text {th }}$ and 8 th, the European Neuroendocrine Tumor Society (ENETS), and the modified ENETS (mENETS) staging systems for well-differentiated pNETs.

\section{Results:}

The proportion of patients with stage III tumors was extremely low (1.1\%) according to the AJCC 7th staging system. For the ENETS staging system, patients with stage IIIA disease had worse estimated mean survival than patients with stage IIIB disease (78.9 vs. 107.3 months). When comparing with patients in stage I, the AJCC 7th, ENETS, and mENETS staging systems showed good performance in discriminating between stages; however, there was no significant difference in some stages when the reference was defined as the earlier stage. When the reference was defined as stage I or the earlier stage, there was a significant inter-stage difference in the AJCC 8th staging system.

\section{Conclusions:}

The AJCC 8th staging system is more suitable for pNETs than other TNM staging systems and may be adopted in clinical practice.

\section{Introduction}

Pancreatic neuroendocrine tumors (pNETs), which account for less than $2 \%$ of all pancreatic tumors, are a group of heterogeneous neoplasms with varying pathologic, functional, and clinical features[1, 2]. With an estimated annual worldwide incidence of 2.5 to 5 per 1,000,000 individuals, pNETs have been increasingly diagnosed over the past several decades, likely due to more accurate classification and improvements in diagnostic tools[3, 4]. Because of their rarity and heterogeneous behavior, it is difficult to stratify pNETs patients into prognostic groups using commonly accepted staging systems[5]. Thus, a robust and accurate staging system for risk stratification and survival prediction is urgently required.

In 2006, the European Neuroendocrine Tumor Society (ENETS) was the first to publish a consensus statement on the TNM staging classification of pNETs, as applied in other solid tumors[6]. Subsequently, the American Joint Committee on Cancer (AJCC) also introduced a TNM staging system for pNETs in 2010 (the AJCC 7th edition), which initially was applied to exocrine pancreatic adenocarcinoma based on studies by Bilimoria et al[5, 7]. Considering the drawbacks of these systems, Luo et al. developed a modified ENETS (mENETS) staging system, which maintained the ENETS T, N, and M definitions and adopted the AJCC system staging definitions[8]. Although several classification schemes have been proposed, there is no commonly accepted staging system (Table 1).

The ENETS staging system pointed out that patients with stage I disease had a similar prognosis to those with stage II disease[9], and the hazard ratio (HR) of death for patients with stage IIIB disease was even lower than that for patients with stage IIIA disease[10]. According to the AJCC 7th staging system, few patients would have stage III disease because pNETs seldom invade the celiac axis or the superior mesenteric artery (unresectable tumor) without distant metastasis, and patients with stage II or III disease were prognostically indistinguishable[11].

In 2017, the AJCC formally introduced a newly revised 8th staging system especially for pNETs, which was somewhat similar to the ENETS criteria, that included several significant changes[12]. First, the AJCC 8th staging system was only applied to welldifferentiated pNETs, whereas poorly differentiated neuroendocrine carcinoma G3 (NEC G3) were excluded and considered according to the staging criteria for pancreatic exocrine adenocarcinoma. Second, it redefined the T, N, M, and staging system; for example, stage II and stage III was defined by combining the 2 previous subgroups of the ENETS system (stage IIA and stage IIB, and stage IIIA and stage IIIB, respectively) (Table 1 ). 
While the new AJCC 8th staging system for well-differentiated pNETs has been validated by some studies[13, 14], validation using a large multi-center cohort has not been performed. Therefore, we utilized a multi-center database to validate the AJCC 8th staging system in the present study. To accomplish this, survival curves were compared according to the AJCC 7th and 8th, the ENETS, and the mENETS staging systems.

\section{Materials And Methods Patients and Data Collection}

The study involved a cohort that included 1086 patients from a multi-center database comprising five Chinese centers and one American center [Wuhan Tongji hospital $(n=153)$, Shanghai Chang Hai hospital $(n=294)$, The First Hospital of Jilin University $(n=$ 92), The Second Hospital of Hebei Medical University $(n=32)$, Shandong Provincial Hospital Affiliated to Shandong University $(n=32)$ and Johns Hopkins Hospital $(n=482)]$.

The main patient variables, including sex, age, tumor location, functional status, operation, type of operation, grade, $\mathrm{T}$ category, $\mathrm{N}$ category, $\mathrm{M}$ category, and overall survival, were all systematically collected and retrieved. We only included patients who had a pathologically confirmed diagnosis of pNET and had complete data to allow restaging per the AJCC and ENETS classifications, including T stage, nodal status, distant metastases, and follow-up data. Patients with NEC G3 tumors were excluded. Electronic datasheets were provided to all participating centers and all de-identified data were reviewed and cross-checked for inconsistencies. The study was approved by the Institutional Review Board of all participating centers.

\section{Statistical analysis}

Survival time was calculated as the number of months from the date of initial diagnosis until the date of last contact or death. Overall survival was evaluated using Kaplan-Meier curves, and log-rank tests were used to assess staging classification. Cox proportional hazards regression was performed for univariate analysis, and the HR and $95 \%$ confidence intervals $(95 \% \mathrm{Cl})$ were calculated. Multivariate analysis of each staging classification, controlling for sex, age, tumor location, functional status, type of operation, and grade, was performed using Cox proportional hazards regression. Values are expressed as number and percentage. All tests were 2sided and statistical significance was defined as $p<0.05$. Statistical analyses were performed using SPSS v22.0 (IBM, Armonk, NY).

\section{Results}

\section{Patient characteristics}

In total, the study included 1086 patients from the multicenter database. Table 2 show their baseline characteristics. The median age was 54 years (mean, 53.27 years) and the proportions of male patients was $50.4 \%$. Most patients had nonfunctioning pNETs (90.1\%) and more than half $(56.3 \%)$ had tumors located at the body and/or tail of the pancreas. Distal pancreatectomy and pancreaticoduodenectomy were performed in 531 (48.9\%) and 398 (36.6\%) patients, respectively, and laparoscopic surgery was conducted in 214 (19.7\%). The median survival was 136.8 months (3-year survival rate, 90.6\%; 5-year survival rate, 83.9\%; 10-year survival rate, $57.6 \%)$.

\section{TNM staging classification and survival}

As shown in Fig. 1 ( $A$ and B) and Table 2, there was no significant difference in overall survival between T3 and T4 in the AJCC 7th T category and the ENETS \& AJCC 8th T category $(P=0.321$ and $\mathrm{p}=0.645$, respectively). According to the AJCC 7 th $\mathrm{T}$ category, only 13 patients (1.2\%) had T4 disease, and they exhibited abnormal survival rates (with $\mathrm{T} 1$ as the reference, $\mathrm{HR}=2.772,95 \% \mathrm{Cl}=0.325$ to $12.297, P=0.180$ ). By contrast, there were significant differences in the $\mathrm{N}$ and $\mathrm{M}$ categories $(\mathrm{HR}=2.418,95 \% \mathrm{Cl}=1.809$ to $3.231, P$ $<0.001 ; \mathrm{HR}=2.621,95 \% \mathrm{Cl}=1.880$ to $3.654, P<0.001$, respectively).

\section{AJCC 7th stage group and survival}

According to the AJCC 7th staging classification, only 12 (1.1\%) of patients had stage III tumors. Compared to patients with stage IA disease, stage III patients showed no significant difference in survival $(\mathrm{HR}=2.076,95 \% \mathrm{Cl}=0.265$ to $16.232, P=0.486)$. In addition, there was no significant differences between stages IIA, IIB, III, and IV when the reference was defined as the earlier stage $(P=0.052, P$ $=0.128, P=0.249$, and $P=0.138$, respectively) (Fig. 1E and Table 2). 
In comparison with patients with stage I disease, a significant difference was observed across all stage groups. However, patients with stage IIIA disease had worse estimated mean survival than patients with IIIB (78.9 vs. 107.3 months). Furthermore, there were also no significant differences across stages IIIA, IIIB, and IV when the reference was defined as the earlier stage $(P=0.978, P=0.411$, and $P$ $=0.077$, respectively) (Fig. $1 \mathrm{~F}$ and Table 2).

\section{mENETS stage group and survival}

The mENETS staging classification showed better distinction between different stages than the AJCC 7th and ENETS systems. There was a significant difference in survival between all stage groups compared to patients with stage I disease, and the relative risk for death was correlated with advanced stage disease. Nevertheless, there were also no significant differences in stages IIB, III, and IV when the reference was defined as the earlier stage $(P=0.158, P=0.691$, and $P=0.139$, respectively) (Fig. $1 \mathrm{G}$ and Table 2.)

\section{AJCC 8th stage group and survival}

Because stages II and III were both previously divided into 2 previous subgroups in the ENETS system (stage IIA and stage IIB, stage IIIA and stage IIIB, respectively), the AJCC 8th staging system divided all patients into four stages. Compared with stage I disease, there was a significant difference between all stages, which was also observed when the reference was defined as the earlier stage (Fig. $1 \mathrm{H}$ and Table 2).

\section{Univariate and multivariate analysis of factors associated with survival}

In the univariate analysis, age $\geq 60$ years $(\mathrm{HR}=1.554,95 \% \mathrm{Cl}=1.156$ to $2.088, P=0.003)$, functional status (function) (HR $=0.272$, $95 \% \mathrm{Cl}=0.128$ to $0.580, P=0.001)$, and grade $(\mathrm{G} 2)$ disease $(\mathrm{HR}=1.534,95 \% \mathrm{Cl}=1.126$ to $2.091, P=0.007)$ were found to be significantly associated with survival (Table 2). In the multivariate analysis, different TNM staging classification (AJCC 7th system, ENETS system, mENETS system and AJCC 8th system, respectively), and age $\geq 60$ years were identified as independent prognostic factors for overall survival (Table 3).

\section{Discussion}

Although the ENETS system is widely used in Europe, and the AJCC system in the United States[15], there is still no widely accepted staging system for pNETs as they are heterogeneous neoplasms with different clinical features, biological behaviors, and prognoses[5]. The current study used a large, multicenter database to validate the newly developed AJCC 8th staging system for welldifferentiated pNETs.

The TNM staging system is widely used for solid tumor staging guidelines, including pNETs[16], with the main guidelines currently available being the AJCC 7th and 8th systems, the ENETS system, and the mENETS system. Each of these exhibits both similarities and differences.

Both the AJCC 7th and ENETS systems have been widely used in clinical practice for a long time. The AJCC 7th staging system adopted the staging system of exocrine pancreatic carcinomas for pNETs, T4 was defined as patients with involvement of the celiac axis or superior mesenteric artery (unresectable tumor), which meant that a very low proportion of patients were considered stage III (T4, any N, M0)[17]. Consistent with the literature, our multicenter cohort had a low proportion of stage III disease (1.1\%). In addition, the presence of extra-pancreatic spread was difficult to assess pathologically due to the expansive growth pattern common to pNETs[13]. Furthermore, some studies found that the AJCC 7th staging system has a poor ability to differentiate between the prognoses of some subgroups. Rindi et al[18] identified 1072 pNETs patients from eight European cancer centers (1990-2007) and found no significant difference in mortality between stages IIA and IIB (death rate per 100 persons per year $=3.4$ vs 3.7, respectively; $\mathrm{HR}$ of death $=25.2,95 \% \mathrm{Cl}=5.9$ to $106.9, P=0.84$ ), and stages IIB and III (death rate per 100 persons per year $=3.4$ and 3.4, respectively; $\mathrm{HR}$ of death $=25.1,95 \% \mathrm{Cl}=5.4$ to $116.5, P=1.0)$. Our study also exhibited similar results, where there was no significant difference across stages IIA, IIB, III, and IV when the reference was defined as the earlier stage $(P=0.052, \mathrm{p}=0.128, P=0.249$, and $P=$ 0.138 , respectively). 
The ENETS system's ability to predict the prognosis of specific groups of patients was considered to be possibly superior to the AJCC 7th system. However, some studies have suggested that ENETS system cannot appropriately discriminate the prognoses of stage I and stage II patients[9], and predicted some abnormal survival outcomes between stages IIIA and IIIB[10]. Luo et al.[8] investigated the SEER database $(\mathrm{N}=2529$ patients $)$ and a multicenter database $(\mathrm{N}=1143$ patients $)$ and confirmed that patients with stage I disease had a similar prognosis to those with stage IIA disease (with stage I as the reference: SEER series, HR=0.99, $P=0.955$; multicenter series, $\mathrm{HR}=1.41, P=0.337$ ) using the ENETS staging system. In addition, the HR of death for patients with stage IIIA disease was even higher than that for patients with stage IIIB disease (with stage I as the reference: SEER series, HR of death $=2.87$ vs. 2.77, respectively; multicentric series, HR of death $=4.56$ vs. 4.25 , respectively). In our study, there were no significant differences in stages IIIA, IIIB, and IV when the reference was defined as the previous stage $(P=0.978, P=0.411$, and $P=0.077$, respectively).

Maintaining the ENETS's T, N, and M definitions and adopting the AJCC system's staging definitions, Luo et al.[4] developed the mENETS, which solved the problem of the low proportion of patients of stage III in the AJCC 7th staging system and the poor differentiation between stages I stage II in the ENETS staging system. However, it became clear that the system showed poor ability to distinguish between the prognoses of stages IA and IB. Meanwhile, the prognostic difference between IIB stage III stage was slightly worse than other subgroups. In the present study, there was also no significant difference across stages IIB, III, and IV when the reference was defined as the previous stage $(P=0.158, P=0.691$ and $P=0.139$, respectively). Thus, the use of complex staging methods may not have much added value when considering diagnoses in the clinical setting.

In 2017, the AJCC 8th staging system, which followed the ENETS's definition of T and simplified the original staging criteria, was introduced by the AJCC specifically for well-differentiated pNETs. The AJCC 8th staging system was no longer suitable for poorly differentiated neuroendocrine carcinoma (G3), which have a significantly worse prognosis, and divided all patients into four stages. In fact, some studies have confirmed that there was no significant difference in survival between patients with stage IIIA or IIIB disease according to the ENETS system[13]. Thus, simplifying and merging some subgroups may be acceptable and may be more practical for determining the clinical prognosis of patients with pNETs. In this study, we confirmed that the AJCC 8th staging system succeeded in classifying patients into 4 significantly different staging groups using our multicenter database, and the relative risk for death was closely correlated with advanced stage disease.

Eschewing the TNM staging system, the World Health Organization published their histologic grade (G) classification based on Ki-67 expression and mitotic counts. The classification was principally to be used for prognostic stratification and determining the adjuvant chemotherapy strategy according to the accurate measurement of proliferation[14]. In the present study, patients with G1 disease exhibited a better estimated 5-year survival rate than patients with G2 (87.1\% vs. $81.6 \%)$, and histologic grade was found to be associated with overall survival in the univariate analysis $(\mathrm{G} 2$ : $\mathrm{HR}=1.534,95 \% \mathrm{Cl}=1.126$ to $2.091, P=0.007)$. The functional status of pNETs also has a significant effect on the prognosis. Studies have confirmed that functional pNETs have better prognoses than nonfunctional pNETs[19]. Consistent with the literature, the estimated 5-year survival rate of patients with functional and non-functional pNETs in our study were $95.0 \%$ and $82.5 \%$, respectively. Functional status was also identified as significant positive prognostic factor in the univariate analysis $(\mathrm{HR}=0.272,95 \% \mathrm{Cl}=0.128$ to $0.580, P=0.001)$.

Although the AJCC 8th staging system is superior to other TNM staging systems and may bring a unified consensus on TNM staging, it failed to include the histologic grade and functional status, which ultimately lead to its limitations in prognosis prediction. Therefore, a new stage classification combining the TNM staging system and G grade is needed to help guide therapeutic decisions.

Furthermore, novel surveillance guidelines need to be developed and trialed.

The major limitation of this study was the retrospective nature of the data analysis. Furthermore, the lack of postoperative course data and postoperative chemotherapy information, among other variables, meant that their significance could not be assessed out. Furthermore, since some patients underwent enucleation, the postoperative lymph node assessment may not be accurate.

\section{Conclusions}

The AJCC 8th staging system is more suitable for pNETs compared to the AJCC 7th, the ENETS, and the mENETS staging systems, and may be adopted in clinical practice. Using this novel system, a consensus on the TNM staging classification of pNETs may soon be reached.

\section{Abbreviations}


pNETs

pancreatic neuroendocrine tumors

AJCC

American Joint Committee on Cancer

ENETS

European Neuroendocrine Tumor Society

mENETS

modified European Neuroendocrine Tumor Society

HR

hazard ratio

\section{Declarations}

\section{Ethics approval and consent to participate}

The current study was conducted in accordance with the Declaration of Helsinki principles and was approved by the Ethics Review Board of the Tongji Hospital of Huazhong University of Science and Technology. (Approval number: TJ-JRB20190418).

\section{Consent for publication}

Not applicable.

\section{Availability of data and materials}

The datasets used and/or analysed during the current study are available from the corresponding author on reasonable request.

\section{Competing interests}

The authors declare that they have no competing interests.

\section{Funding}

This study was supported by grants from The National Natural Science Foundation of China (81772950 to RY Q, 81773160 to MW, 81702792 to SM X, 81502633 to XL, 81602475 to XJ G, 81874205 to FZ); Tongji Hospital Clinical Research Flagship Program (2019CR203) to RY Q; Hubei Natural Science Foundation (2017CFB467), National Key Research and Development Program of China (2019TFC1315905) and Tongji Hospital Science Fund for Distinguished Young Scholars (2017) to MW. The authors declare no relevant conflicts of interest.

\section{Authors' contributions}

HBW, JHL, YHL, MW, and RYQ designed the study. JL, HZ, JFZ, CHW, AJ, CW, SWG, QMC, WHZ, WS, FZ, XJG, XL, FP, RZH, SMX, JKJ, AN, BE, YWT, GJ, LZ, and JH collated the data. HBW, DD, TTQ, and MW carried out data analyses and produced the initial draft of the manuscript. HBW, JHL, YHL, MW, and RYQ contributed to drafting the manuscript. All authors have read and approved the final submitted manuscript.

\section{Acknowledgements}

We would like to thank Editage (www.editage.com) for English language editing.

\section{References}

1. Hallet J, Law CHL, Cukier M, Saskin R, Liu N, Singh S. Exploring the rising incidence of neuroendocrine tumors: a populationbased analysis of epidemiology, metastatic presentation, and outcomes. Cancer. 2015;121(4):589-97.

2. Yao JC, Eisner MP, Leary C, Dagohoy C, Phan A, Rashid A, et al. Population-based study of islet cell carcinoma. Ann Surg Oncol. 2007;14(12):3492-500. 
3. Fitzgerald TL, Hickner ZJ, Schmitz M, Kort EJ. Changing incidence of pancreatic neoplasms: a 16-year review of statewide tumor registry. Pancreas. 2008;37(2):134-8.

4. Keutgen XM, Nilubol N, Kebebew E. Malignant-functioning neuroendocrine tumors of the pancreas: A survival analysis. Surgery. 2016;159(5):1382-9.

5. Bilimoria KY, Bentrem DJ, Merkow RP, Tomlinson JS, Stewart AK, Ko CY, et al. Application of the pancreatic adenocarcinoma staging system to pancreatic neuroendocrine tumors. J Am Coll Surg. 2007;205(4):558-63.

6. Rindi G, Klöppel G, Alhman H, Caplin M, Couvelard A, de Herder WW, et al. TNM staging of foregut (neuro)endocrine tumors: a consensus proposal including a grading system. Virchows Arch. 2006;449(4):395-401.

7. Ellison TA, Wolfgang CL, Shi C, Cameron JL, Murakami P, Mun LJ, et al. A single institution's 26-year experience with nonfunctional pancreatic neuroendocrine tumors: a validation of current staging systems and a new prognostic nomogram. Ann Surg. 2014;259(2):204-12.

8. Luo G, Javed A, Strosberg JR, Jin K, Zhang Y, Liu C, et al. Modified Staging Classification for Pancreatic Neuroendocrine Tumors on the Basis of the American Joint Committee on Cancer and European Neuroendocrine Tumor Society Systems. J Clin Oncol. 2017;35(3):274-80.

9. Ekeblad S, Skogseid B, Dunder K, Oberg K, Eriksson B. Prognostic factors and survival in 324 patients with pancreatic endocrine tumor treated at a single institution. Clin Cancer Res. 2008;14(23):7798-803.

10. Scarpa A, Mantovani W, Capelli P, Beghelli S, Boninsegna L, Bettini R, et al. Pancreatic endocrine tumors: improved TNM staging and histopathological grading permit a clinically efficient prognostic stratification of patients. Mod pathol. 2010;23(6):824-33.

11. Rindi G, Falconi M, Klersy C, Albarello L, Boninsegna L, Buchler MW, et al. TNM staging of neoplasms of the endocrine pancreas: results from a large international cohort study. J Natl Cancer Inst. 2012;104(10):764-77.

12. Yang M, Zhang Y, Zeng L, Ke N-W, Tan C-L, Tian B-I, et al. Prognostic Validity of the American Joint Committee on Cancer Eighth Edition TNM Staging System for Surgically Treated and Well-Differentiated Pancreatic Neuroendocrine Tumors: A Comprehensive Analysis of 254 Consecutive Patients From a Large Chinese Institution. Pancreas. 2019;48(5):613-21.

13. You Y, Jang JY, Kim SC, Yoon YS, Park JS, Cho CK, et al. Validation of the 8th AJCC Cancer Staging System for Pancreas Neuroendocrine Tumors Using Korean Nationwide Surgery Database. Cancer Res Treat. 2019;51(4):1639-52.

14. Choe J, Kim KW, Kim HJ, Kim DW, Kim KP, Hong SM, et al. What Is New in the 2017 World Health Organization Classification and 8th American Joint Committee on Cancer Staging System for Pancreatic Neuroendocrine Neoplasms? Korean J Radiol. 2019;20(1):5-17.

15. Klöppel G, Rindi G, Perren A, Komminoth P, Klimstra DS. The ENETS and AJCC/UICC TNM classifications of the neuroendocrine tumors of the gastrointestinal tract and the pancreas: a statement. Virchows Arch. 2010;456(6):595-7.

16. Amin MB, Greene FL, Edge SB, Compton CC, Gershenwald JE, Brookland RK, et al. The Eighth Edition AJCC Cancer Staging Manual: Continuing to build a bridge from a population-based to a more "personalized" approach to cancer staging. CA Cancer J Clin. 2017;67(2):93-9.

17. Kamarajah SK, Burns WR, Frankel TL, Cho CS, Nathan H. Validation of the American Joint Commission on Cancer (AJCC) 8th Edition Staging System for Patients with Pancreatic Adenocarcinoma: A Surveillance, Epidemiology and End Results (SEER) Analysis. Ann Surg Oncol. 2017;24(7):2023-30.

18. Rindi G, Falconi M, Klersy C, Albarello L, Boninsegna L, Buchler MW, et al. TNM staging of neoplasms of the endocrine pancreas: results from a large international cohort study. J Natl Cancer Inst. 2012;104(10):764-77.

19. Ishida H, Lam AK-Y. Pancreatic neuroendocrine neoplasms: The latest surgical and medical treatment strategies based on the current World Health Organization classification. Crit Rev Oncol Hematol. 2020;145:102835.

\section{Tables}

Table 1. Staging definition of the various staging systems for pancreatic neuroendocrine tumor. 


\begin{tabular}{|c|c|c|c|c|c|c|c|}
\hline & \multicolumn{4}{|c|}{ AJCC 7th stage system } & \multicolumn{3}{|c|}{ ENETS, mENETS and AJCC 8th stage system } \\
\hline T1 & \multicolumn{4}{|c|}{ Limited to the pancreas, $\mathrm{Z} \leq 2 \mathrm{~cm}$ in greatest dimension } & \multicolumn{3}{|c|}{ Tumor limited to the pancreas, $<2 \mathrm{~cm}$} \\
\hline $\mathrm{T} 2$ & \multicolumn{4}{|c|}{ Limited to the pancreas, $>2 \mathrm{~cm}$ in greatest dimension } & \multicolumn{3}{|c|}{ Tumor limited to the pancreas, $2-4 \mathrm{~cm}$} \\
\hline T3 & \multicolumn{4}{|c|}{$\begin{array}{l}\text { Beyond the pancreas but without involvement of the superior } \\
\text { mesenteric artery }\end{array}$} & \multicolumn{3}{|c|}{$\begin{array}{l}\text { Tumor limited to the pancreas, }>4 \mathrm{~cm} \text {, or invading the } \\
\text { duodenum or common bile duct }\end{array}$} \\
\hline T4 & \multicolumn{4}{|c|}{$\begin{array}{l}\text { Involvement of the celiac axis or superior mesenteric artery } \\
\text { (unresectable tumor) }\end{array}$} & \multicolumn{3}{|c|}{$\begin{array}{l}\text { Tumor invades adjacent organs (stomach, spleen. colon, } \\
\text { adrenal gland) or the wall of large vessels (celiac axis or } \\
\text { the superior mesenteric artery) }\end{array}$} \\
\hline No & \multicolumn{7}{|c|}{ No regional lymph node metastasis } \\
\hline N1 & \multicolumn{7}{|c|}{ Regional lymph node metastasis } \\
\hline M0 & \multicolumn{7}{|c|}{ No distant metastasis } \\
\hline M1 & \multicolumn{7}{|c|}{$\begin{array}{l}\text { Distant metastasis (M1aß̧: metastasis confined to liver; } \\
\text { M1b§్ : metastasis in at least one extrahepatic site; M1ç: } \\
\text { both hepatic and extrahepatic metastases) }\end{array}$} \\
\hline \multicolumn{8}{|c|}{ AJCC 7th and mENETS stages } \\
\hline Stage & $\mathrm{T}$ & $\mathrm{N}$ & M & Stage & $\mathrm{T}$ & $\mathrm{N}$ & M \\
\hline $\mathrm{IA}$ & $\mathrm{T} 1$ & No & M0 & 1 & $\mathrm{~T} 1$ & No & M0 \\
\hline $\mathrm{IB}$ & $\mathrm{T} 2$ & No & MO & $\|(A) q$ & $\mathrm{~T} 2$ & No & Mo \\
\hline IIA & T3 & No & MO & $\|(B) \uparrow$ & T3 & No & Mo \\
\hline IIB & T1-3 & N1 & MO & $\operatorname{III}(\mathrm{A}) \mathrm{q}$ & $\mathrm{T} 4$ & NO & Mo \\
\hline III & $\mathrm{T} 4$ & Any $\mathrm{N}$ & MO & $\| I I(B) \uparrow$ & Any $T$ & N1 & Mo \\
\hline IV & Any $T$ & Any N & M1 & IV & Any $\mathrm{T}$ & Any N & M1 \\
\hline
\end{tabular}

Table 2. Baseline clinicopathologic characteristics and univariate analysis of prognostic factors for overall survival. 


\begin{tabular}{|c|c|c|c|c|c|c|}
\hline & \multicolumn{2}{|c|}{$\begin{array}{l}\text { Multicenter database } \\
(n=1086)\end{array}$} & \multicolumn{3}{|c|}{ Univariate analysis } & \\
\hline & No. & $\%$ & $\mathrm{HR}$ & $95 \% \mathrm{Cl}$ & $P$ value & \\
\hline \multicolumn{7}{|l|}{ Sex } \\
\hline Male & 547 & 50.4 & 1 & & & \\
\hline Female & 539 & 49.6 & 0.802 & $0.600-1.072$ & 0.136 & \\
\hline \multicolumn{7}{|l|}{ Age, years } \\
\hline$<60$ & 726 & 66.9 & 1 & & & \\
\hline$\geq 60$ & 360 & 33.1 & 1.554 & $1.156-2.088$ & 0.003 & \\
\hline Tumor location & & & & & 0.079 & \\
\hline Head/uncinate & 450 & 41.4 & 1 & & & \\
\hline Body/tail & 611 & 56.3 & 0.732 & $0.547-0.979$ & 0.035 & \\
\hline Other & 25 & 2.3 & 0.539 & $0.170-1.713$ & 0.295 & \\
\hline \multicolumn{7}{|l|}{ Functional status } \\
\hline Nonfunctional & 978 & 90.1 & 1 & & & \\
\hline functional & 108 & 9.9 & 0.272 & $0.128-0.580$ & 0.001 & \\
\hline Operation & & & & & 0.054 & \\
\hline Pancreaticoduodenectomy & 398 & 36.6 & 1 & & & \\
\hline Distal pancreatectomy & 531 & 48.9 & 0.710 & $0.523-0.965$ & 0.029 & \\
\hline Enucleation & 153 & 14.1 & 0.574 & $0.354-0.932$ & 0.025 & \\
\hline Others & 4 & 0.4 & 0 & 0 & 0.944 & \\
\hline \multicolumn{7}{|l|}{ Type of operation } \\
\hline Open & 872 & 80.3 & 1 & & & \\
\hline Laparoscopic & 214 & 19.7 & 1.121 & $0.772-1.629$ & 0.548 & \\
\hline \multicolumn{7}{|l|}{ Grade } \\
\hline G1 & 483 & 44.5 & 1 & & & \\
\hline $\mathrm{G} 2$ & 603 & 55.5 & 1.534 & $1.126-2.091$ & 0.007 & \\
\hline AJCC 7th T category & & & & & $<0.001$ & \\
\hline T1 & 335 & 30.8 & 1 & & & \\
\hline $\mathrm{T} 2$ & 433 & 39.9 & 3.524 & $1.956-6.347$ & $<0.001$ & \\
\hline T3 & 305 & 28.1 & 5.634 & $3.147-10.086$ & $<0.001$ & $0.002 \S$ \\
\hline $\mathrm{T} 4$ & 13 & 1.2 & 2.772 & $0.325-12.297$ & 0.180 & $0.321 \S$ \\
\hline ENETS\& AJCC 8th T category & & & & & $<0.001$ & \\
\hline T1 & 315 & 29.0 & 1 & & & \\
\hline $\mathrm{T} 2$ & 410 & 37.8 & 3.261 & $1.764-6.029$ & $<0.001$ & \\
\hline T3 & 256 & 23.6 & 5.618 & $3.066-10.296$ & $<0.001$ & $0.001 \S$ \\
\hline $\mathrm{T} 4$ & 105 & 9.7 & 6.365 & $3.030-13.371$ & $<0.001$ & $0.645 \S$ \\
\hline
\end{tabular}

Page 10/14 


\begin{tabular}{|c|c|c|c|c|c|c|}
\hline & \multicolumn{2}{|c|}{$\begin{array}{l}\text { Multicenter database } \\
(n=1086)\end{array}$} & \multicolumn{4}{|c|}{ Univariate analysis } \\
\hline \multicolumn{7}{|l|}{$\mathrm{N}$ category } \\
\hline NO & 838 & 77.2 & 1 & & & \\
\hline $\mathrm{N} 1$ & 248 & 22.8 & 2.418 & $1.809-3.231$ & $<0.001$ & \\
\hline \multicolumn{7}{|l|}{ M category } \\
\hline MO & 973 & 89.6 & 1 & & & \\
\hline M1 & 113 & 10.4 & 2.621 & $1.880-3.654$ & $<0.001$ & \\
\hline AJCC 7th stage group & & & & & $<0.001$ & \\
\hline IA & 294 & 27.1 & 1 & & & \\
\hline IB & 306 & 28.2 & 2.984 & $1.493-5.964$ & 0.002 & \\
\hline$\| A$ & 180 & 16.6 & 4.729 & $2.323-9.625$ & $<0.001$ & $0.052 \S$ \\
\hline IIB & 181 & 16.7 & 6.644 & $3.379-13.063$ & $<0.001$ & $0.128 \S$ \\
\hline III & 12 & 1.1 & 2.076 & $0.265-16.232$ & 0.486 & $0.249 \S$ \\
\hline IV & 113 & 10.4 & 9.315 & $4.697-17.471$ & $<0.001$ & $0.138 \S$ \\
\hline ENETS stage group & & & & & $<0.001$ & \\
\hline I & 279 & 25.7 & 1 & & & \\
\hline$\| \mathrm{A}$ & 310 & 28.5 & 2.597 & $1.293-5.219$ & 0.007 & \\
\hline IIB & 128 & 11.8 & 4.376 & $2.130-8.990$ & $<0.001$ & $0.035 \S$ \\
\hline IIIA & 69 & 6.4 & 4.322 & $1.563-11.948$ & 0.005 & $0.978 \S$ \\
\hline IIIB & 187 & 17.2 & 6.178 & $3.145-12.136$ & $<0.001$ & $0.411 \S$ \\
\hline IV & 113 & 10.4 & 8.778 & $4.426-17.410$ & $<0.001$ & $0.077 \S$ \\
\hline mENETS stage group & & & & & $<0.001$ & \\
\hline IA & 279 & 25.7 & 1 & & & \\
\hline IB & 310 & 28.5 & 2.594 & $1.291-5.213$ & 0.007 & \\
\hline$\| A$ & 128 & 11.8 & 4.371 & $2.127-8.979$ & $<0.001$ & $0.035 \S$ \\
\hline IIB & 162 & 14.9 & 6.078 & $3.077-12.044$ & $<0.001$ & $0.158 \S$ \\
\hline III & 94 & 8.7 & 5.314 & $2.248-12.563$ & $<0.001$ & $0.691 \S$ \\
\hline IV & 113 & 10.4 & 8.771 & $4.422-17.396$ & $<0.001$ & $0.139 \S$ \\
\hline AJCC 8th stage group & & & & & $<0.001$ & \\
\hline I & 279 & 25.7 & 1 & & & \\
\hline ॥ & 438 & 40.3 & 3.145 & $1.617-6.119$ & $<0.001$ & \\
\hline III & 256 & 23.6 & 5.925 & $3.033-11.573$ & $<0.001$ & $<0.001 \S$ \\
\hline IV & 113 & 10.4 & 8.762 & $4.417-17.379$ & $<0.001$ & $0.044 \S$ \\
\hline
\end{tabular}

Table 3. Multivariate analysis of prognostic factors for overall survival. 


\begin{tabular}{|c|c|c|c|c|c|c|c|c|c|c|c|c|}
\hline & \multicolumn{3}{|c|}{$\begin{array}{l}\text { AJCC 7th system } \\
\text { multivariable analysis }\end{array}$} & \multicolumn{3}{|c|}{$\begin{array}{l}\text { ENETS system } \\
\text { multivariable analysis }\end{array}$} & \multicolumn{3}{|c|}{$\begin{array}{l}\text { mENETS system } \\
\text { multivariable analysis }\end{array}$} & \multicolumn{3}{|c|}{$\begin{array}{l}\text { AJCC 8th system } \\
\text { multivariable analysis }\end{array}$} \\
\hline & $\mathrm{HR}$ & $95 \% \mathrm{Cl}$ & $\begin{array}{l}\mathrm{P} \\
\text { value }\end{array}$ & $\mathrm{HR}$ & $95 \% \mathrm{Cl}$ & $\begin{array}{l}P \\
\text { value }\end{array}$ & $\mathrm{HR}$ & $95 \% \mathrm{Cl}$ & $\begin{array}{l}\mathrm{P} \\
\text { value }\end{array}$ & $\mathrm{HR}$ & $95 \% \mathrm{Cl}$ & $\begin{array}{l}\mathrm{P} \\
\text { value }\end{array}$ \\
\hline \multicolumn{13}{|l|}{ Sex } \\
\hline Male & 1 & & & 1 & & & 1 & & & 1 & & \\
\hline Female & 0.836 & $\begin{array}{l}0.321- \\
1.125\end{array}$ & 0.237 & 0.839 & $\begin{array}{l}0.326- \\
1.129\end{array}$ & 0.246 & 0.833 & $\begin{array}{l}0.619- \\
1.122\end{array}$ & 0.229 & 0.808 & $\begin{array}{l}0.602- \\
1.084\end{array}$ & 0.154 \\
\hline \multicolumn{13}{|l|}{ Age, years } \\
\hline$<60$ & 1 & & & 1 & & & 1 & & & 1 & & \\
\hline$\geq 60$ & 1.493 & $\begin{array}{l}1.107- \\
2.014\end{array}$ & 0.009 & 1.500 & $\begin{array}{l}1.112- \\
2.024\end{array}$ & 0.008 & 1.498 & $\begin{array}{l}1.111- \\
2.022\end{array}$ & 0.008 & 1.506 & $\begin{array}{l}1.117- \\
2.032\end{array}$ & 0.007 \\
\hline \multicolumn{13}{|l|}{$\begin{array}{l}\text { Tumor } \\
\text { location }\end{array}$} \\
\hline Head/uncinate & 1 & & & 1 & & & 1 & & & 1 & & \\
\hline Body/tail & 0.841 & $\begin{array}{l}0.625- \\
1.132\end{array}$ & 0.254 & 0.830 & $\begin{array}{l}0.616- \\
1.118\end{array}$ & 0.220 & 0.818 & $\begin{array}{l}0.606- \\
1.103\end{array}$ & 0.187 & 0.811 & $\begin{array}{l}0.604- \\
1.090\end{array}$ & 0.165 \\
\hline Other & 0.558 & $\begin{array}{l}0.169- \\
1.844\end{array}$ & 0.338 & 0.565 & $\begin{array}{l}0.171- \\
1.868\end{array}$ & 0.349 & 0.560 & $\begin{array}{l}0.169- \\
1.855\end{array}$ & 0.343 & 0.645 & $\begin{array}{l}0.199- \\
2.093\end{array}$ & 0.465 \\
\hline \multicolumn{13}{|l|}{$\begin{array}{l}\text { Functional } \\
\text { status }\end{array}$} \\
\hline Nonfunctional & 1 & & & 1 & & & 1 & & & 1 & & \\
\hline Functional & 0.510 & $\begin{array}{l}0.235- \\
1.106\end{array}$ & 0.088 & 0.504 & $\begin{array}{l}0.233- \\
1.092\end{array}$ & 0.082 & 0.498 & $\begin{array}{l}0.230- \\
1.079\end{array}$ & 0.077 & 0.494 & $\begin{array}{l}0.228- \\
1.070\end{array}$ & 0.074 \\
\hline \multicolumn{13}{|l|}{$\begin{array}{l}\text { Type of } \\
\text { operation }\end{array}$} \\
\hline Open & 1 & & & 1 & & & 1 & & & 1 & & \\
\hline Laparoscopic & 0.957 & $\begin{array}{l}0.655- \\
1.399\end{array}$ & 0.820 & 0.955 & $\begin{array}{l}0.654- \\
1.395\end{array}$ & 0.813 & 0.953 & $\begin{array}{l}0.653- \\
1.393\end{array}$ & 0.805 & 0.969 & $\begin{array}{l}0.663- \\
1.414\end{array}$ & 0.869 \\
\hline \multicolumn{13}{|l|}{ Grade } \\
\hline G1 & 1 & & & 1 & & & 1 & & & 1 & & \\
\hline $\mathrm{G} 2$ & 1.283 & $\begin{array}{l}0.934- \\
1.761\end{array}$ & 0.124 & 1.288 & $\begin{array}{l}0.937- \\
1.770\end{array}$ & 0.119 & 1.281 & $\begin{array}{l}0.932- \\
1.761\end{array}$ & 0.127 & 1.322 & $\begin{array}{l}0.965- \\
1.812\end{array}$ & 0.083 \\
\hline \multicolumn{13}{|l|}{$\begin{array}{l}\text { AJCC 7th } \\
\text { stage group }\end{array}$} \\
\hline IA & 1 & & & & & & & & & & & \\
\hline IB & 2.744 & $\begin{array}{l}1.367- \\
5.511\end{array}$ & 0.005 & & & & & & & & & \\
\hline IIA & 4.060 & $\begin{array}{l}1.975- \\
8.346\end{array}$ & $\dot{0} 001$ & & & & & & & & & \\
\hline IIB & 5.248 & $\begin{array}{l}2.639- \\
10.434\end{array}$ & $\begin{array}{l}< \\
0.001\end{array}$ & & & & & & & & & \\
\hline III & 2.051 & $\begin{array}{l}0.261- \\
16.097\end{array}$ & 0.495 & & & & & & & & & \\
\hline IV & 7.675 & $\begin{array}{l}3.820- \\
15.417\end{array}$ & $\begin{array}{l}< \\
0.001\end{array}$ & & & & & & & & & \\
\hline
\end{tabular}

Page 12/14 


\begin{tabular}{|c|c|c|c|c|c|c|c|c|c|c|}
\hline & $\begin{array}{l}\text { AJCC 7th system } \\
\text { multivariable analysis }\end{array}$ & \multicolumn{3}{|c|}{$\begin{array}{l}\text { ENETS system } \\
\text { multivariable analysis }\end{array}$} & \multicolumn{3}{|c|}{$\begin{array}{l}\text { mENETS system } \\
\text { multivariable analysis }\end{array}$} & \multicolumn{3}{|c|}{$\begin{array}{l}\text { AJCC 8th system } \\
\text { multivariable analysis }\end{array}$} \\
\hline \multicolumn{11}{|c|}{$\begin{array}{l}\text { ENETS stage } \\
\text { group }\end{array}$} \\
\hline I & & 1 & & & & & & & & \\
\hline$\| A$ & & 2.412 & $\begin{array}{l}1.196- \\
4.866\end{array}$ & 0.014 & & & & & & \\
\hline IIB & & 3.696 & $\begin{array}{l}1.777- \\
7.685\end{array}$ & $<.001$ & & & & & & \\
\hline IIIA & & 3.906 & $\begin{array}{l}1.401- \\
10.892\end{array}$ & 0.009 & & & & & & \\
\hline IIIB & & 4.912 & $\begin{array}{l}2.475- \\
9.750\end{array}$ & $<.001$ & & & & & & \\
\hline IV & & 7.223 & $\begin{array}{l}3.595- \\
14.512\end{array}$ & $<.001$ & & & & & & \\
\hline \multicolumn{11}{|c|}{$\begin{array}{l}\text { mENETS } \\
\text { stage group }\end{array}$} \\
\hline IA & \multicolumn{10}{|c|}{1} \\
\hline IB & & & & & 2.408 & $\begin{array}{l}1.193- \\
4.858\end{array}$ & 0.014 & & & \\
\hline IIA & & & & & 3.685 & $\begin{array}{l}1.772- \\
7.662\end{array}$ & $\begin{array}{l}< \\
0.001\end{array}$ & & & \\
\hline IIB & & & & & 4.749 & $\begin{array}{l}2.378- \\
9.482\end{array}$ & $\begin{array}{l}<.001 \\
0.00\end{array}$ & & & \\
\hline III & & & & & 4.885 & $\begin{array}{l}2.049- \\
11.649\end{array}$ & $<001$ & & & \\
\hline IV & & & & & 7.208 & $\begin{array}{l}3.588- \\
14.482\end{array}$ & $<.001$ & & & \\
\hline \multicolumn{11}{|c|}{$\begin{array}{l}\text { AJCC 8th } \\
\text { stage group }\end{array}$} \\
\hline I & & & & & \multicolumn{6}{|c|}{1} \\
\hline II & & & & & & & & 2.817 & $\begin{array}{l}1.441- \\
5.507\end{array}$ & 0.002 \\
\hline III & & & & & & & & 4.757 & $\begin{array}{l}2.415- \\
9.369\end{array}$ & $<.001$ \\
\hline IV & & & & & & & & 7.135 & $\begin{array}{l}3.553- \\
14.328\end{array}$ & $<.001$ \\
\hline
\end{tabular}

\section{Figures}



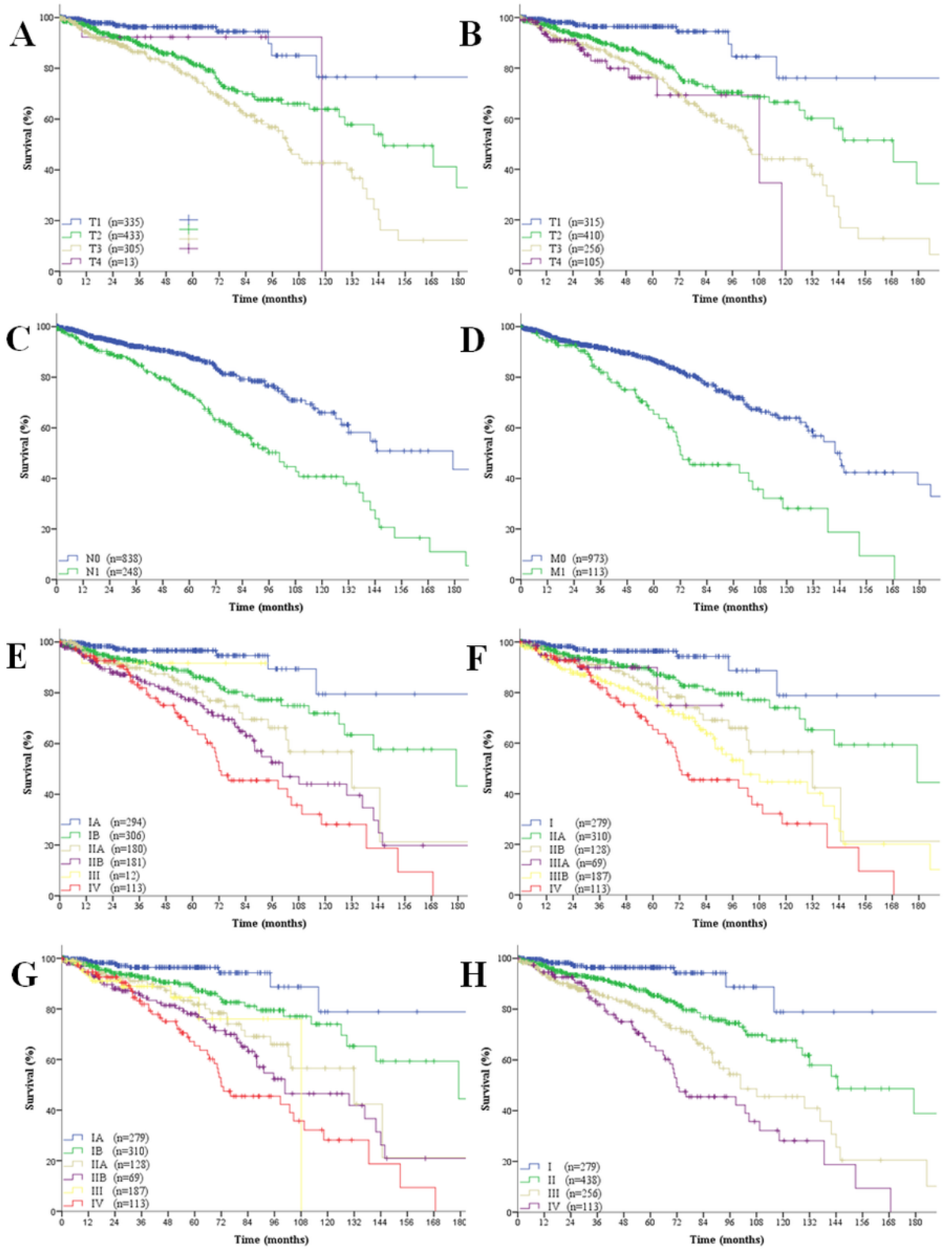

\section{Figure 1}

Kaplan-Meier analysis of overall survival. (A) T category of the American Joint Committee on Cancer (AJCC) 7th edition, (B) T category of the European Neuroendocrine Tumor Society (ENETS) and AJCC 8th edition, (C) N category, (D) M category, (E) 7th AJCC stage group, (F) ENETS stage group, (G) modified ENETS (mENETS) stage group, (H) 8th AJCC stage group. 